Check for updates

Cite this: Chem. Sci., 2019, 10, 5843

๑ All publication charges for this article have been paid for by the Royal Society of Chemistry

Received 12th March 2019

Accepted 9th May 2019

DOI: $10.1039 / c 9 s c 01229 j$

rsc.li/chemical-science

\section{Ferroelectric metallomesogens composed of achiral spin crossover molecules $\dagger$}

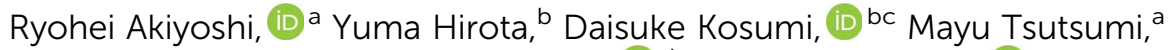 \\ Masaaki Nakamura, ${ }^{a}$ Leonard F. Lindoy (D) d and Shinya Hayami (D) *ac
}

Ferroelectric liquid crystals (FLCs) are fascinating functional materials that have a remnant and electrically invertible polarization. To date, typical FLCs have been mainly realized by molecular design such as the incorporation of chirality into a given molecular structure. Here, we report for the first time ferroelectricity induced by spin transition associated with a crystal - liquid crystal phase transition in achiral molecules. Iron(II) metallomesogens incorporating alkyl chains of type $\left[\mathrm{Fe}\left(3 \mathrm{C}_{n}-\text { bzimpy }\right)_{2}\right]\left(\mathrm{BF}_{4}\right)_{2}(n$ $=8$ (1), 10 (2), 12 (3), 14 (4), 16 (5) and 18 (6); bzimpy = 2,6-bis(benzimidazol-2'-yl)pyridine) that exhibit spin crossover (SCO) phenomena have been synthesized. Compounds 5 and 6 were each demonstrated to show SCO behaviour along with the occurrence of a phase transition between the crystalline $(\mathrm{Cr})$ state and corresponding chiral smectic $\mathrm{C}\left(\mathrm{SmC}^{*}\right)$ state. The distortion of the coordination sphere in the high spin state is seen to trigger the generation of the $\mathrm{SmC}^{*}$ state. The liquid crystalline compounds do not display ferroelectric behaviour in their $\mathrm{Cr}$ state but do exhibit ferroelectric hysteresis loops in their SmC* state. Ferroelectric switching was clearly confirmed by second harmonic generation (SHG) experiments involving the respective phases. These findings will undoubtedly lead to new strategies for the design of new FLCs based on metal-centred spin transitions.

\section{Introduction}

Ferroelectric liquid crystals (FLCs) ${ }^{\mathbf{1 , 2}}$ have attracted considerable attention due to their potential application for use in fast switching devices, rewritable memories and nonlinear optics..$^{3-6}$ In general, such FLCs have involved chiral molecules and, in particular, the introduction of chirality has been thought to be crucially important in the case of rod-like or disk-like FLC molecules., ${ }^{2,-11}$ However, FLCs based on banana-shaped molecules, free of molecular chirality, were reported in $1996 .^{\mathbf{1 2}}$ Subsequently, considerable effort has been applied to the investigation of bent molecules as achiral alternatives to chiral(or racemic mixture-) based FLCs. ${ }^{13-18}$

\footnotetext{
${ }^{a}$ Department of Chemistry, Graduate School of Science and Technology, Kumamoto University, 2-39-1 Kurokami, Chuo-ku, Kumamoto, 860-8555, Japan. E-mail: hayami@kumamoto-u.ac.jp

${ }^{b}$ Department of Physics, Graduate School of Science and Technology, Kumamoto University, 2-39-1 Kurokami, Chuo-ku, Kumamoto, 860-8555, Japan

'Institute of Pulsed Power Science (IPPS), Kumamoto University, 2-39-1 Kurokami, Chuo-ku, Kumamoto 860-8555, Japan

${ }^{d}$ School of Chemistry, The University of Sydney, NSW 2006, Australia

$\dagger$ Electronic supplementary information (ESI) available: Experimental procedures, crystal parameters, single crystal X-ray structure, DSC curves, POM textures, PXRD patterns, CD spectra, dielectric constants, $P-E$ hysteresis curves, SHG experiments, $\chi_{\mathrm{m}} T$ (and DSC) vs. $T$ plots, Mössbauer spectra and Mössbauer fitting parameters. CCDC 1416013 and 1908948. For ESI and crystallographic data in CIF or other electronic format see DOI: $10.1039 / \mathrm{c} 9 \mathrm{sc} 01229 \mathrm{j}$
}

Recently, metal-containing LCs, the metallomesogens, ${ }^{\mathbf{1 9 , 2 0}}$ have been widely investigated because they often exhibit interesting physical properties, including magnetic, electrical and optical properties, that are associated with the metal ion species in the anisotropic phases. ${ }^{21-23}$ Largely directed by metal ion complexation, various structural types of ferroelectric metallomesogens, including banana, ${ }^{24,25}$ open-book, ${ }^{26} \mathrm{~K}$ or $\mathrm{H}$ shape, ${ }^{27-30}$ brick-like ${ }^{31,32}$ and square pyramidal ${ }^{24,33}$ geometries have been constructed. In addition, we have reported $\left[\mathrm{M}\left(\mathrm{X}-4 \mathrm{C}_{18^{-}}\right.\right.$ salmmen)] $\left(\mathrm{M}=\mathrm{Zn}\right.$ and $\mathrm{Pt}, \mathrm{X}=R, S$ and rac; salmmen $=N, N^{\prime}-$ monomethylene-bis-salicylideneimine) complexes that displayed both ferroelectricity and luminescence properties even though racemic forms were present. ${ }^{24}$ In prior studies, most of the reported ferroelectric metallomesogens incorporated organic ligands containing chiral substituents and the role of their structural features in influencing their ferroelectricity and associated physical properties has in general been readily rationalized. On the other hand, reports of ferroelectric metallomesogens (and associated properties) whose ferroelectricity is based on the geometry of a central metal ion are limited up to now. In particular, the prospect of a correlation occurring between magnetic and ferroelectric properties in FLCs remains largely unexplored, despite the possibility that such magnetoelectric effects might be anticipated to occur.

SCO metallomesogens are a new category of functional materials which have been found to synchronize SCO and LC properties. $^{34-40}$ In this context it is noted that SCO phenomena 
may occur in transition metal complexes with $\mathrm{d}^{n}(n=4-7)$ electronic configurations on switching between their low spin (LS) and high spin (HS) states reversibly; such SCO can be induced by an external perturbation (such as a change in temperature, pressure, magnetic field or light irradiation). ${ }^{\mathbf{4 1 - 4 4}}$ SCO behaviour gives rise to significant structural changes, primarily involving metal-ligand bond lengths and angles that, in turn, lead to distortion of the coordination sphere (Fig. 1). ${ }^{\mathbf{4 5 - 4 9}}$ Thus, the dipole moments necessary for inducing ferroelectricity can in principle be generated via the LS $\leftrightarrow$ HS transition associated with the corresponding structural perturbation.

Herein, we report examples of SCO-triggered FLCs of type $\left[\mathrm{Fe}\left(3 \mathrm{C}_{n} \text {-bzimpy }\right)_{2}\right]\left(\mathrm{BF}_{4}\right)_{2}$ in the absence of molecular chirality (see Fig. 2 for an explanation of the abbreviations; $n=8$ (1), 10 (2), 12 (3), 14 (4), 16 (5) and 18 (6)). Compounds 5 and 6 have been demonstrated to exhibit SCO behaviour involving a crystalline (Cr) - chiral smectic C (SmC*) transformation, with ferroelectric switching being observed in the $\mathrm{SmC}^{*}$ phase.

\section{Results and discussion}

\section{Synthesis and crystal structure}

The iron(II) metallomesogens, [Fe(3C $n$-bzimpy $\left.)_{2}\right]\left(\mathrm{BF}_{4}\right)_{2}(n=8$ (1), 10 (2), 12 (3), 14 (4), 16 (5) and 18 (6)), each incorporating six alkyl chains, were synthesized by reaction between $\mathrm{Fe}\left(\mathrm{BF}_{4}\right)_{2}$ $\cdot 4 \mathrm{H}_{2} \mathrm{O}$ and $3 \mathrm{C}_{n}$-bzimpy according to the previously reported procedure. ${ }^{50}$ The structure of $5 \cdot 2 \mathrm{H}_{2} \mathrm{O}$ was determined at $93 \mathrm{~K}$ by a single crystal X-ray structural analysis. This compound crystallized in the triclinic $P \overline{1}$ space group. Crystal data are shown in Table S1. $\dagger$ The Fe-N bond lengths are 1.969(6) A, 1.912(6) A,

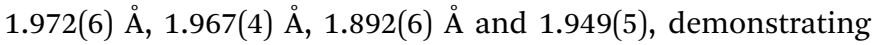
that $5 \cdot 2 \mathrm{H}_{2} \mathrm{O}$ is in its LS state at $93 \mathrm{~K}$. This compound has an asymmetric structure in which two alkyl chains are located on one side of the complex "core" while the other four alkyl chains are positioned on the opposite side as shown in Fig. S1a. $\dagger$ The packing structure shows hydrophilic areas incorporating metal complex centres and two $\mathrm{BF}_{4}{ }^{-}$of counter anions together with two water molecules (Fig. S1c $\dagger$ ). Hydrophobic areas in which $\pi-$ $\pi$ interactions occur between bzimpy ligands as well as

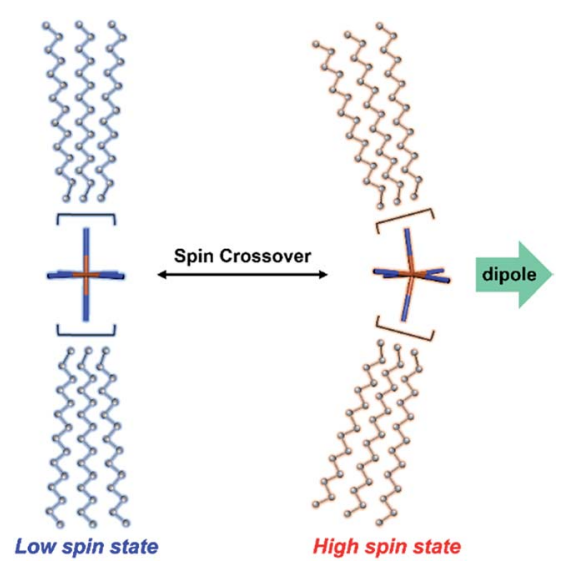

Fig. 1 Schematic illustration of the generation of a diple moment via SCO.

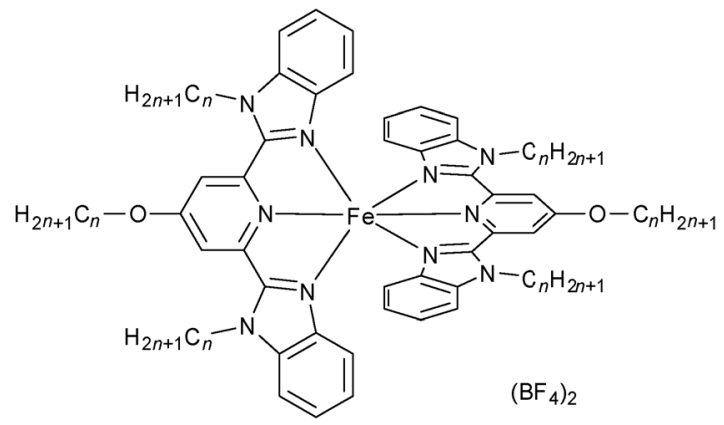

Fig. 2 Structure of $\left[\mathrm{Fe}\left(3 \mathrm{C}_{n} \text {-bzimpy }\right)_{2}\right]\left(\mathrm{BF}_{4}\right)_{2}(n=8$ (1), 10 (2), 12 (3), 14 (4), $16(5), 18(6))$

hydrophobic interactions between alkyl chains in neighbouring molecules, are present. In order to investigate the "undiluted" LC, magnetic properties and ferroelectricity, we carried out thermal treatments for 1-6 at their melting points for 1 hour to remove their water molecules before undertaking the LC and magnetic characterizations discussed below.

\section{LC behaviours}

The multiple phase and LC properties were investigated using differential scanning calorimetry (DSC), temperaturedependent powder X-ray diffraction (PXRD) measurements and polarized optical microscopy (POM) observation. Phase transition temperatures obtained from the DSC experiments in the 2 nd heating mode are summarized in Fig. 3. Compounds 1 and 2 showed two DSC peaks (exo and endothermic), and arising from isotropic liquid (IL) - Cr and $\mathrm{Cr}$ - IL by supercooling (Fig. S2 $\dagger$ ). In contrast, 3-6 have multiphase natures. Upon heating from room temperature, 3 and 4 exhibited SmC*$\mathrm{Cr}, \mathrm{Cr}-\mathrm{SmC}^{*}, \mathrm{SmC}^{*}-\mathrm{SmA}, \mathrm{SmA}-\mathrm{IL}$ phase transitions in turn (one exo and three endothermic peaks). DSC curves for 5 and 6 also show four phase transitions corresponding to $\mathrm{Cr}_{1}-\mathrm{Cr}_{2}, \mathrm{Cr}_{2}-$ SmC*, SmC*-SmA, and SmA-IL transitions with four DSC endothermic peaks. The different phase transformation and

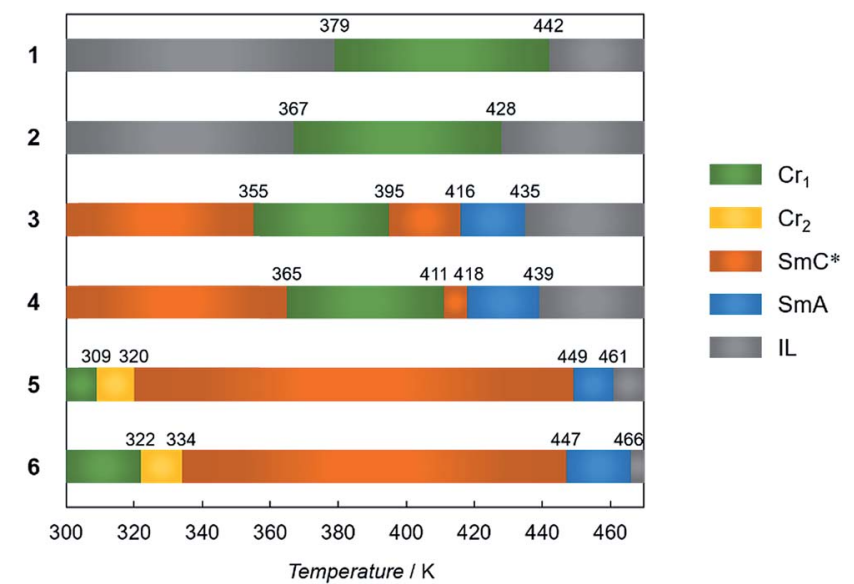

Fig. 3 Phase transition temperatures of 1-6 determined by DSC measurement $\left(5 \mathrm{~K} \mathrm{~min}^{-1}\right)$ in the 2 nd heating mode. 
transition temperatures arise from the different strengths of inter-chain interaction present (that in turn reflect the respective carbon numbers in the incorporated alkyl chains).

Polarized optical microscopy (POM) determined textures of 5 are presented in Fig. $4 \mathrm{a}$ and b. The SmA mesophases yielded fan-shape textures while fingerprint textures were obtained for the $\mathrm{SmC}^{*}$ phases, with chirality being demonstrated by active circular dichroism (CD) spectra for the textures obtained for SmC* (Fig. 4c). POM textures for $\mathbf{3}, \mathbf{4}$ and $\mathbf{6}$ are shown in Fig. S3 $\dagger$ which also shows fingerprint textures for the $\mathrm{SmC}^{*}$ state and fan-shape textures for the SmA phase. The LC natures are corroborated by the results of PXRD analyses in which diffraction patterns for the mesophases have sharp peaks in the small angle region and broad scattering halos in the wide angle region. The $d$ spacing values calculated from the (001) peaks, are $25.1 \AA$ for $3,29.0 \AA$ for $\mathbf{4}, 33.5 \AA$ for $\mathbf{5}$ and $36.3 \AA$ for $\mathbf{6}$ in the SmC* states, smaller than $25.8 \AA$ for $\mathbf{3}, 31.9 \AA$ for $\mathbf{4}, 35.4 \AA$ for $\mathbf{5}$ and $39.0 \AA$ for $\mathbf{6}$ in the SmA states, respectively. However, in the case of 1 and 2, LC properties were not observed, as shown by the variable temperature PXRD patterns, in which sharp peaks were maintained in the wide-angle region.

\section{Ferroelectric properties}

The SmC* mesophase is potentially capable of showing ferroelectric properties. The temperature dependences of the dielectric constants for 3-6 in the frequency range of $100 \mathrm{~Hz}$ to 1 $\mathrm{kHz}$ were measured using an impedance analyser in the heating mode to investigate the electric field responses to the phase transitions (Fig. S6 †). The dielectric constants for 3 and 4
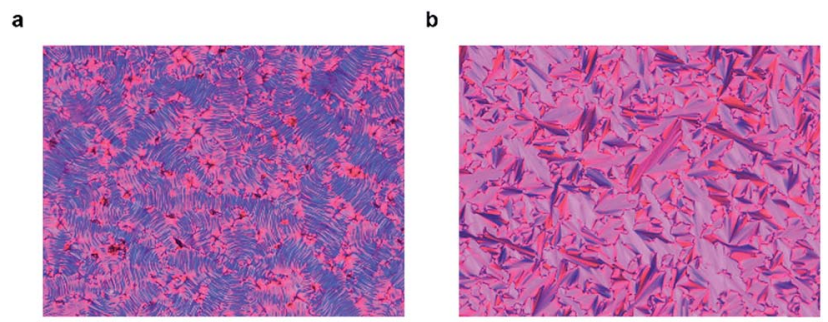

c

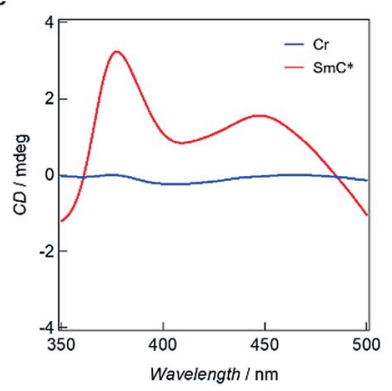

d

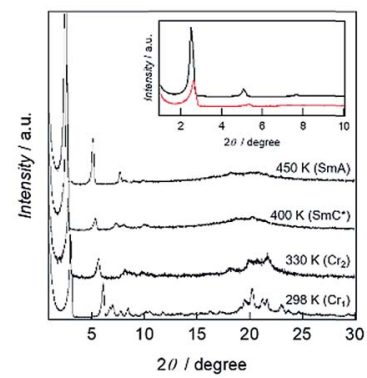

Fig. 4 (a) POM textures for the SmC* state at $384 \mathrm{~K}$ and (b) the SmA state at $449 \mathrm{~K}$ in 5 . (c) CD spectra for 5 at $298 \mathrm{~K}$ (blue line: $\mathrm{Cr}$ state, red line: SmC* state). The spectrum for SmC* was obtained using the sample cooled to room temperature after melting. The observed fingerprint-shape texture in the $\mathrm{SmC}$ * state was maintained at room temperature. (d) Temperature-dependent PXRD patterns for 5 . The inset shows the PXRD patterns for SmC* (red line) and SmA (black line) states. remained unchanged between 200 and $350 \mathrm{~K}$. On further heating above $350 \mathrm{~K}$, the elevation of the dielectric constants was observed. As for $\mathbf{5}$ and $\mathbf{6}$, the dielectric constants are almost constant at the temperatures of the $\mathrm{Cr}$ states but are abruptly increased on accomplishing the $\mathrm{Cr}-\mathrm{SmC}$ * transition. A dielectric constant determined at $1 \mathrm{kHz}$ is significantly smaller than one obtained at $100 \mathrm{~Hz}$ because the metal complex dipole moments become less sensitive to the electric field at this higher frequency.

The ferroelectric behaviour of each of the phases observed for 3-6 were analysed using polarization vs. electric field $(P-E)$ curves with the aid of a TF Analyzer1000. The temperature rising for $P-E$ measurements was performed at $5 \mathrm{~K} \mathrm{~min}^{-1}$. For $\mathbf{5}$, no ferroelectric hysteresis loop resulting in ferroelectricity was observed for the Cr state (Fig. 5a blue line). On the other hand, the ferroelectric hysteresis loop was clearly evident for the $\mathrm{SmC}^{*}$ state, with the remnant polarization being $19.4 \mathrm{nC}$ (Fig. 5a red line). Compounds 3, 4 and 6 also gave ferroelectric hysteresis curves with obvious remnant polarizations in the $\mathrm{SmC}^{*}$ state that were similar to that of $\mathbf{5}$ (see Fig. S7†).

The presence of ferroelectricity was supported by second harmonic generation (SHG) experiments for the respective phases using an excitation wavelength of $1080 \mathrm{~nm}$. A strong SHG intensity was evident for 5 at $c a .540 \mathrm{~nm}$ for the SmC* phase (Fig. 5b), while no SHG occurred for the Cr state, with respectively 3, 4, and 6 showing similar behaviour to this (Fig. S8 ${ }^{\dagger}$ ). Accordingly, these results are in keeping with the resultant polarization leading to the expression of ferroelectricity in the above systems.

\section{Magnetic properties}

The magnetic behaviours of 1-6 were determined using a SQUID magnetometer before and after melting the respective samples. For the solvated compounds 1-6, the $\chi_{\mathrm{m}} T$ values were closed to zero and corresponded to iron(II) LS diamagnetism before melting and below $300 \mathrm{~K}$. On heating over $300 \mathrm{~K}$, the $\chi_{\mathrm{m}} T$ values increased because of removing solvent water molecules (Fig. S9†). Thermal treatments for solvated 1-6 were carried out
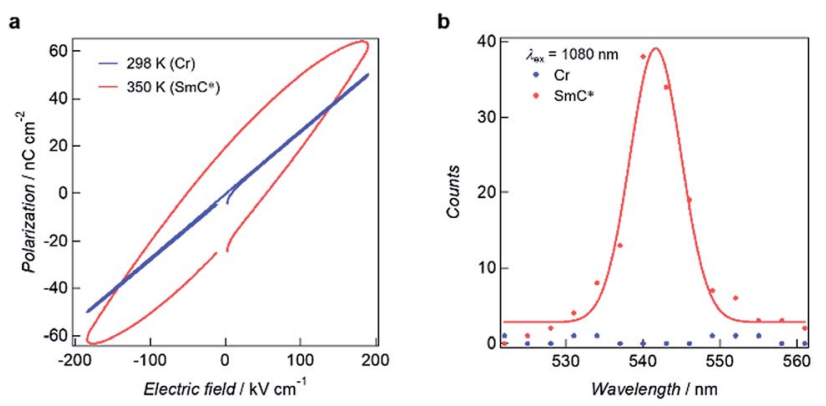

Fig. 5 (a) Temperature-dependent $P-E$ hysteresis curves for 5 at $100 \mathrm{~Hz}$ (blue line: $298 \mathrm{~K}$ ( $\mathrm{Cr}$ state), red line: $350 \mathrm{~K}$ (SmC* state)). (b) Results of SHG experiments on 5 at 298 K. The SmC* sample for SHG experiments was prepared by cooling it to room temperature after melting. The observed fingerprint-shape texture in the $\mathrm{SmC}^{*}$ state was maintained at room temperature (blue plot: $\mathrm{Cr}$ state, red plot: $\mathrm{SmC}$ * state). 


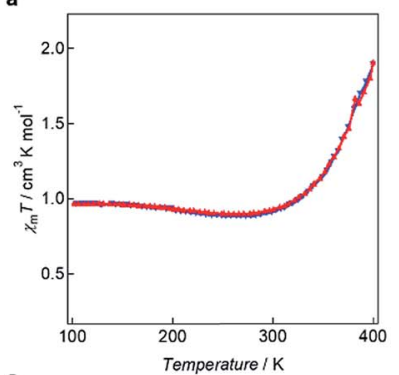

c

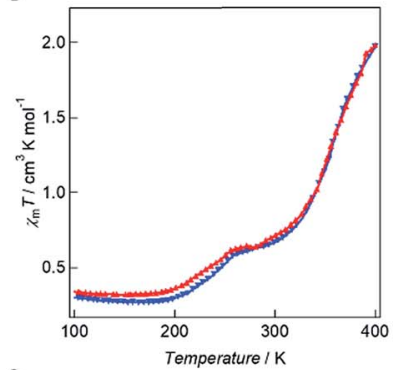

e

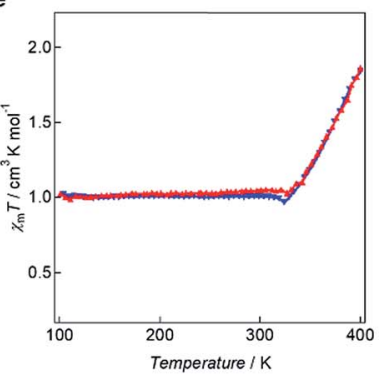

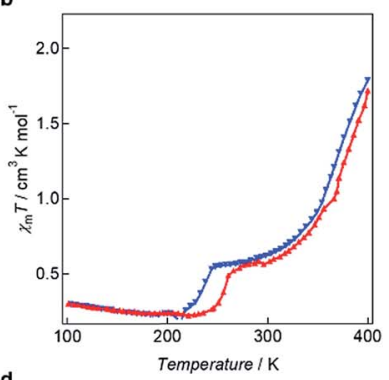

d
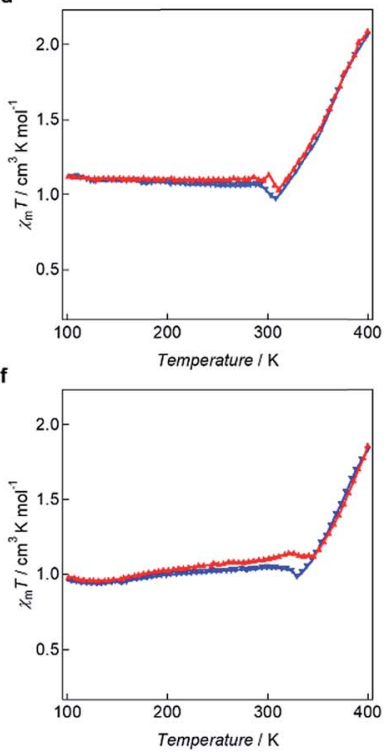

Fig. $6 \chi_{m} T$ vs. $T$ plots for (a) 1, (b) 2, (c) 3, (d) 4, (e) 5 and (f) 6 (red plot: heating, blue plot: cooling).

in order to remove the effects of solvent on the magnetism (Fig. 6). For 1, gradual SCO was observed, and the $\chi_{\mathrm{m}} T$ value increased from $0.966 \mathrm{~cm}^{3} \mathrm{~K} \mathrm{~mol}^{-1}$ at $100 \mathrm{~K}$ to $1.906 \mathrm{~cm}^{3} \mathrm{~K} \mathrm{~mol}^{-1}$ at $400 \mathrm{~K}$. For 2 and 3, two step SCO was observed, and the $\chi_{\mathrm{m}} T$ value was unchanged between 100 and $200 \mathrm{~K}$. Upon further heating above $200 \mathrm{~K}$, the $\chi_{\mathrm{m}} T$ value increased to $0.517 \mathrm{~cm}^{3} \mathrm{~K}$ $\mathrm{mol}^{-1}$ for 2 and $0.626 \mathrm{~cm}^{3} \mathrm{~K} \mathrm{~mol}^{-1}$ for 3 and then again to 1.717 $\mathrm{cm}^{3} \mathrm{~K} \mathrm{~mol}^{-1}$ (for 2) and $1.979 \mathrm{~cm}^{3} \mathrm{~K} \mathrm{~mol}^{-1}$ (for 3) at $400 \mathrm{~K}$. In DSC measurements for $\mathbf{2}$ and 3, there is no peak in the two step SCO temperatures. The origin of two step may be complicate structural changes in alkyl chains. The compounds 4-6 also exhibit gradual SCO behaviours with " $\chi_{\mathrm{m}} T$ jump". In the case of 4 , upon heating, the $\chi_{\mathrm{m}} T$ value at $100 \mathrm{~K}$ is $1.120 \mathrm{~cm}^{3} \mathrm{~K} \mathrm{~mol}^{-1}$ and remains close to this value $\left(1.050 \mathrm{~cm}^{3} \mathrm{~K} \mathrm{~mol}^{-1}\right)$ at $301 \mathrm{~K}$, demonstrating that the spin state of the metal centre remains unaltered at $301 \mathrm{~K}$. From $301 \mathrm{~K}$ to $311 \mathrm{~K}$, the $\chi_{\mathrm{m}} T$ value decreases to $1.038 \mathrm{~cm}^{3} \mathrm{~K} \mathrm{~mol}^{-1}$. Subsequently, the $\chi_{\mathrm{m}} T$ value increases gradually and reaches $2.088 \mathrm{~cm}^{3} \mathrm{~K} \mathrm{~mol}^{-1}$ at $400 \mathrm{~K}$. For 5 , the $\chi_{\mathrm{m}} T$ value at $101 \mathrm{~K}$ is $1.022 \mathrm{~cm}^{3} \mathrm{~K} \mathrm{~mol}^{-1}$ and rises slightly to $1.050 \mathrm{~cm}^{3} \mathrm{~K} \mathrm{~mol}^{-1}$ at $321 \mathrm{~K}$ but then decreases slightly to $1.026 \mathrm{~cm}^{3} \mathrm{~K} \mathrm{~mol}^{-1}$ at $327 \mathrm{~K}$, followed by a large increase to 1.861 $\mathrm{cm}^{3} \mathrm{~K} \mathrm{~mol}^{-1}$ at $400 \mathrm{~K}$. A "jump" in the observed $\chi_{\mathrm{m}} T$ value for 5 is assigned to result from the $\mathrm{Cr}-\mathrm{SmC}^{*}$ phase transition. The $\chi_{\mathrm{m}} T$ value for 6 at $100 \mathrm{~K}$ is $0.981 \mathrm{~cm}^{3} \mathrm{~K} \mathrm{~mol}^{-1}$ and this value

gradually increases to $1.141 \mathrm{~cm}^{3} \mathrm{~K} \mathrm{~mol}^{-1}$ at $321 \mathrm{~K}$. The $\chi_{\mathrm{m}} T$ value then shows a decrease to $1.094 \mathrm{~cm}^{3} \mathrm{~K} \mathrm{~mol}^{-1}$ which is similar behaviour to that observed for 5 . The value for 6 then starts to increase at $344 \mathrm{~K}$ to reach $1.858 \mathrm{~cm}^{3} \mathrm{~K} \mathrm{~mol}^{-1}$ at $400 \mathrm{~K}$.

The observed " $\chi_{\mathrm{m}} T$ jump" clearly reflect the corresponding Cr-SmC* phase transitions observed in the respective DSC analyses. The temperatures at which the $\chi_{\mathrm{m}} T$ values start to slightly decrease, namely $321 \mathrm{~K}$ for 5 and $323 \mathrm{~K}$ for $\mathbf{6}$, are in very good agreement with the phase transition temperatures for the $\mathrm{Cr}$ state transforming to the corresponding SmC* state observed in the 2 nd heating processes (Fig. S10 $\dagger$ ). These occur at 320 and 334 respectively (Fig. 3), indicating that these CrSmC* phase transitions are directly related to the SCO behaviour. Although negligible thermal hysteresis was observed for 2 over the heating and cooling process, for 1-6 the behaviours in the cooling processes retrace almost the same paths observed for their respective heating processes. The high $\chi_{\mathrm{m}} T$ values $\left(\chi_{\mathrm{m}} T\right.$ $\approx 1.0$ ) of $1,4,5$ and 6 were observed below $300 \mathrm{~K}$. In order to confirm the induction of the magnetic behaviours, Mössbauer spectra for 5 were measured at $100 \mathrm{~K}$ before and after melting (Fig. S11 and Table S2 $\dagger$ ). Before melting, a narrow doublet with Q.S. (quadrupole splitting) $=0.58 \mathrm{~mm} \mathrm{~s}^{-1}$ and I.S. (isomer shift) $=0.34 \mathrm{~mm} \mathrm{~s}^{-1}$ was observed, which corresponded to the LS state of iron(II) compounds. After melting, a wide doublet with Q.S. $=2.79 \mathrm{~mm} \mathrm{~s}^{-1}$ and I.S. $=0.96 \mathrm{~mm} \mathrm{~s}^{-1}$ was appeared, showing that the iron(II) takes the HS state. The ratio of HS and LS at $100 \mathrm{~K}$ was $3: 7$ after melting. It is thought that the high $\chi_{\mathrm{m}} T$ values were caused by trapping the iron(II) HS state below the freezing point.

\section{SCO behaviours associated with crystal - liquid crystal phase transitions}

As mentioned above, compounds represented by 5 and 6 exhibit SCO that is synchronized with a phase transition from their $\mathrm{Cr}$ state to their corresponding $\mathrm{SmC}^{*}$ state. In order to generate such SCO metallomesogens, both the number and the lengths of the alkyl chains that are appended to the metal complex cores are important. Thus, we have reported previously that $\left[\mathrm{Fe}\left(1 \mathrm{C}_{16^{-}}\right.\right.$ bzimpy $\left.)_{2}\right]\left(\mathrm{BF}_{4}\right)_{2}$ (Fig. S12a $\dagger$ ) incorporating only two alkyl chains undergoes its SCO from LS to HS below the LC transition temperature of $547 \mathrm{~K}$ because inter-chain interaction involving just two alkyl chains is not sufficient to maintain the LS state while $\left[\mathrm{Fe}\left(2 \mathrm{C}_{16} \text {-bzimpy }\right)_{2}\right]\left(\mathrm{BF}_{4}\right)_{2}$ (Fig. S12b $\dagger$ ) incorporating four alkyl chains showed no SCO behaviour. ${ }^{51}$ The presence of six alkyl chains in each of $\mathbf{5}$ and $\mathbf{6}$ is clearly important for maintaining the LS state below the phase transition, leading to the respective observed synchronized behaviour between SCO and LC transitions. Moreover, our results demonstrated that the LC transition temperature can be tuned by varying the carbon numbers of the incorporated alkyl chains. Thus, on increasing the carbon numbers, the LC transition temperature is increased in accord with stronger inter-chain interactions occurring (Fig. 3). On the other hand, no LC properties were evident for the compounds incorporating alkyl chains with $n=8$ or 10 because of weak inter-chain interaction. 


\section{SCO-induced ferroelectricity}

In order to further discuss the SCO-induced ferroelectricity, zinc(II) metallomesogen of type $\left[\mathrm{Zn}\left(3 \mathrm{C}_{16} \text {-bzimpy }\right)_{2}\right]\left(\mathrm{BF}_{4}\right)_{2}(7)$ was synthesized and investigated about the liquid crystal property and ferroelectric behaviour. The crystal structure of 7 are determined at $200 \mathrm{~K}$, which is an isostructure with the compound 5 (Fig. S13 $\dagger$ ). In the compound 7, the two alkyl chains are located on one side of metal complex core while the other four alkyl chains are positioned on the opposite side to the two alkyl chains. From the results of DSC experiment, the compound 7 also shows phase transition including $\mathrm{Cr}_{1}-\mathrm{Cr}_{2}, \mathrm{Cr}_{2}-\mathrm{SmC}^{*}$, SmC*-SmA and SmA-IL in the 2 nd heating process as same as that of 5 (Fig. S14 $\dagger$ ). Although the SmA phase were not determined in the temperature-dependent PXRD patterns because of very short temperature region, the POM textures are clearly indicative of fan-shape texture typically observed in the SmA state (Fig. S15b $\dagger$ ). The dielectric constant for 7 remained unchanged between 200 and $350 \mathrm{~K}$. On further heating above $350 \mathrm{~K}$, the elevation of the dielectric constant was observed (Fig. S16 $\dagger$ ). As presented in Fig. S17a, $\dagger$ the $P-E$ curves for the compound 7 displayed a ferroelectric hysteresis loop with the remnant polarization of $1.16 \mathrm{nC}$ in the $\mathrm{SmC}^{*}$ state. The remnant polarization observed in compound 7 is significantly smaller than that for $\mathbf{5}(19.4 \mathrm{nC})$. Moreover, no SHG intensity was evident in the compound 7 owing to its small remnant polarization (Fig. S17b $\dagger$ ). Therefore, it is clear that the compound 7 shows no ferroelectricity or has at least so small ferroelectric component. Collectively, these results demonstrated that the SCO behaviour (LS to HS transition) in the iron(II) metallomesogens leads to large molecular distortion, and arises the dipole in molecules. As a result, the SCO behaviour associated with a Cr-LC phase transition plays a crucial role in enhancing ferroelectricity.

\section{Conclusions}

In summary, we have developed a new strategy for fabricating FLCs using the iron(II) metallomesogens 1-6 incorporating pairs of bzimpy ligands each bearing three long alkyl chains. From this series, compounds 5 and $\mathbf{6}$ were demonstrated to exhibit SCO behaviour associated with a phase transition from crystalline to $\mathrm{SmC}^{*}$ state. The distortion of the coordination sphere in the HS state is seen to promote the formation of the SmC* phase, resulting in ferroelectric hysteresis loop formation and spontaneous polarization. In past studies a range of ferroelectric metallomesogens have been generated by employing molecules incorporating chiral centres. In contrast, in the present study we demonstrate for the first time that a spin transition accompanied by a crystal - LC phase transition can result in the generation of ferroelectricity. Clearly, our study points the way to the future development of new ferroelectric materials generated in the absence of chirality. We plan further work towards obtaining a range of a new FLC compounds of this type.

\section{Conflicts of interest}

There are no conflicts to declare.

\section{Acknowledgements}

This work was supported by KAKENHI Grant-in-Aid for Scientific Research (A) JP17H01200.

\section{Notes and references}

1 R. B. Meyer, Mol. Cryst. Liq. Cryst., 1977, 40, 33-48.

2 S. T. Lagerwall, Ferroelectrics, 2004, 301, 15-45.

3 D. M. Walba, Science, 1995, 270, 250-251.

4 C. M. Leader, W. Zheng, J. Tipping and H. J. Coles, Liq. Cryst., 1995, 19, 415-419.

5 D. M. Walba, D. J. Dyer, T. Sierra, P. L. Cobben, R. Shao and N. A. Clark, J. Am. Chem. Soc., 1996, 118, 1211-1212.

6 K. E. Maly, M. D. Wand and R. P. Lemieux, J. Am. Chem. Soc., 2002, 124, 7898-7899.

7 D. M. Walba, S. C. Slater, W. N. Thurmes, N. A. Clark, M. A. Handschy and F. Suponlb, J. Am. Chem. Soc., 1986, 108, 5210-5221.

8 J. W. Goodby and E. Chin, Liq. Cryst., 1988, 3, 1245-1254.

9 C. Bahr, G. Heppke and B. Sabaschus, Liq. Cryst., 1991, 9, 3140.

10 A. B. Harris, R. D. Kamien and T. C. Lubensky, Rev. Mod. Phys, 1999, 71, 1745-1757.

11 I. Dierking, Symmetry, 2014, 6, 444-472.

12 T. Niori, T. Sekine, J. Watanabe, T. Furukawa and H. Takezoe, J. Mater. Chem., 1996, 6, 1231-1233.

13 G. Pelzl, S. Diele and W. Weissflog, Adv. Mater., 1999, 11, 707-724.

14 D. M. Walba, E. Korblova, R. Shao, J. E. Maclennan, D. R. Link, M. A. Glaser and N. A. Clark, Science, 2000, 288, 2181-2184.

15 G. Dantlgraber, A. Eremin, S. Diele, A. Hauser, H. Kresse, G. Pelzl and C. Tschierske, Angew. Chem. Int. Ed., 2002, 41, 2408-2412.

16 K. Kishikawa, S. Nakahara, Y. Nishikawa, S. Kohmoto and M. Yamamoto, J. Am. Chem. Soc., 2005, 127, 2565-2571.

17 S. K. Lee, S. Heo, J. G. Lee, K.-T. Kang, K. Kumazawa, K. Nishida, Y. Shimbo, Y. Takanishi, J. Watanabe, T. Doi, T. Takahashi and H. Takezoe, J. Am. Chem. Soc., 2005, 127, 11085-11091.

18 R. A. Reddy and C. Tschierske, J. Mater. Chem., 2006, 16, 907961.

19 A.-M. Giroud-Godquin and P. M. Maitlis, Angew. Chem. Int. Ed., 1991, 30, 375-402.

20 G. Lattrrnznnn, S. Schmidt, R. Kleppinger and J. H. Wendocff, Adv. Mater., 1992, 4, 30-33.

21 K. Binnemans, Y. G. Galyametdinov, R. V. Deun, D. W. Bruce, S. R. Collinson, A. P. Polishchuk, I. Bikchantaev, W. Haase, A. V. Prosvirin, L. Tinchurina, I. Litvinov, A. Gubajdullin, A. Rakhmatullin, K. Uytterhoeven and L. V. Meervelt, J. Am. Chem. Soc., 2000, 122, 4335-4344.

22 K. Binnemans, L. Malykhina, V. S. Mironov, W. Haase, K. Driesen, R. V. Deun, L. Fluyt, C. G. Walrand and Y. G. Galyametdinov, Chem. Phys. Chem., 2001, 11, 680-683. 
23 V. N. Kozhevnikov, B. Donnio, B. Heinrich and D. W. Bruce, Chem. Commun., 2014, 50, 14191-14193.

24 R. Ohtani, M. Nakaya, H. Ohmagari, M. Nakamura, K. Ohta, L. F. Lindoy and S. Hayami, Sci. Rep., 2015, 5, 16606.

25 R. Akiyoshi, Y. Hirota, D. Kosumi, R. Ohtani, M. Nakamura, L. F. Lindoy and S. Hayami, Dalton Trans, 2018, 47, 1428814292.

26 P. Espinet, J. Etxebarria, M. Marcos, J. Perez, A. Remdn and J. L. Serrano, Angew. Chem. Int. Ed., 1989, 28, 1065-1066.

27 M. J. Baena, P. Espinet, M. B. Ros, J. L. Serrano and A. Ezcurra, Angew. Chem. Int. Ed., 1993, 32, 1203-1205.

28 M. J. Baena, J. Barberfi, P. Espinet, A. Ezcurra, M. B. Ros and J. L. Serrano, J. Am. Chem. Soc., 1994, 116, 1899-1906.

29 P. Espinet, J. Etxebarria, C. L. Folcia, J. Ortega, M. B. Ros and J. L. Serrano, Adv. Mater., 1996, 8, 745-748.

30 N. J. Thompson, J. L. Serrano, M. J. Baena and P. Espinet, Chem.-Eur. J, 1996, 2, 214-220.

31 M. Marcos, J. L. Serrano, T. Sierra and M. J. Gimtnez, Angew. Chem. Int. Ed., 1992, 31, 1471-1472.

32 M. Ghedini, D. Pucci, N. Scaramuzza, L. Komitov and S. T. Lagerwall, Adv. Mater., 1995, 7, 659-662.

33 A. Ohta, Y. Yamamoto, H. Kamihata, Y. H. Lee, F. Ichikawa, K. Ohta, Y. Abe, N. Hoshino, M. Kojima and S. Hayami, Inorg. Chem. Commun., 2012, 16, 89-91.

34 S. Hayami, N. Motokawa, A. Shuto, N. Masuhara, T. Someya, Y. Ogawa, K. Inoue and Y. Maeda, Inorg. Chem., 2007, 46, 1789-1794.

35 H. Shinya, M. Reiko, S. Aya, M. Yonezo, O. Kazuchika and I. Katsuya, Inorg. Chem., 2007, 46, 7692-7694.

36 M. Seredyuk, A. B. Gaspar, V. Ksenofontov, Y. Galyametdinov, J. Kusz and P. G. tlich, J. Am. Chem. Soc., 2008, 130, 1431-1439.

37 M. Seredyuk, A. B. Gaspar, V. Ksenofontov, Y. Galyametdinov, J. Kusz and P. Gütlich, Adv. Funct. Mater., 2008, 18, 2089-2101.

38 M. Seredyuk, A. B. Gaspar, V. Ksenofontov, Y. Galyametdinov, M. Verdaguer, F. Villain and P. G. tlich, Inorg. Chem., 2008, 47, 10232-10245.
39 M. Seredyuk, M. C. Munoz, V. Ksenofontov, P. Gutlich, Y. Galyametdinov and J. A. Real, Inorg. Chem., 2014, 53, 8442-8454.

40 R. Akiyoshi, K. Kuroiwa, S. Alao Amolegbe, M. Nakaya, R. Ohtani, M. Nakamura, L. F. Lindoy and S. Hayami, Chem. Commun., 2017, 53, 4685-4687.

41 W.-K. Han, L.-F. Qin, C.-Y. Pang, C.-K. Cheng, W. Zhu, Z.-H. Li, Z. Li, X. Renb and Z.-G. Gu, Dalton Trans, 2017, 46, 8004-8008.

42 V. Jornet-Moll, Y. Duan, C. Gimnez-Saiz, Y.-Y. Tang, P.-F. Li, F. M. Romero and R.-G. Xiong, Angew. Chem. Int. Ed., 2017, 56, 14052-14056.

43 J.-F. Létard, S. e. Montant, P. Guionneau, P. Martin, A. L. Calvez, E. Freysz, D. Chasseau, R. e. Lapouyadea and O. Kahna, Chem. Commun., 1997, 745-746.

44 S. Ohkoshi, S. Takano, K. Imoto, M. Yoshikiyo, A. Namai and H. Tokoro, Nature Photonics, 2013, 8, 65-71.

45 P. Guionneau, M. Marchivie, G. Bravic, J.-F. Létard and D. Chasseau, J. Mater. Chem., 2002, 12, 2546-2551.

46 J. Elhaïk, C. A. Kilner and M. A. Halcrow, Eur. J. Inorg. Chem., 2014, 26, 4250-4253.

47 L. J. K. Cook, R. Mohammed, G. Sherborne, T. D. Roberts, S. Alvarez and M. A. Halcrow, Coord. Chem. Rev., 2015, 289-290, 2-12.

48 W. Phonsri, P. Harding, L. Liu, S. G. Telfer, K. S. Murray, B. Moubaraki, T. M. Ross, G. N. L. Jameson and D. J. Harding, Chem. Sci., 2017, 8, 3949-3959.

49 M. Nakaya, R. Ohtani, J. W. Shin, M. Nakamura, L. F. Lindoy and S. Hayami, Dalton Trans, 2018, 47, 13809-13814.

50 Y. H. Lee, A. Ohta, Y. Yamamoto, Y. Komatsu, K. Kato, T. Shimizu, H. Shinoda and S. Hayami, Polyhedron, 2011, 30, 3001-3005.

51 S. Hayami, N. Motokawa, A. Shuto, R. Moriyama, N. Masuhara, K. Inoue and Y. Maeda, Polyhedron, 2007, 26, 2375-2380. 